\title{
CONTRIBUIÇÃO PARA O ESTUDO DA COM- POSIÇÃO E VALOR NUTRITIVO DE PLANTAS FORRAGEIRAS
}

\author{
W. R. JARDIM \\ Prof. Catedratico \\ C. LEMAIRE DE MORAES \\ Assistente
}

A. M. PEIXOTO

Assistente

INDICE

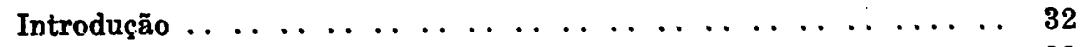

Material e $\mathbf{M}$ étodos $\ldots \ldots \ldots \ldots \ldots \ldots$

Resultados . . . . . . . . . . . . . . . . . . . . . . . . . . . . 34

Resumo e Conclusões . . . . . . . . . . . . . . . . . . . . . . . 37

Abstract $\ldots \ldots \ldots \ldots \ldots$

Bibliografia $\ldots \ldots \ldots \ldots \ldots$ 
I PARTE

\section{INTRODUÇAOO}

O presente trabalho é o primeiro de uma série que os autores pretendem efetuar, tendo por firn o conhecimento da composição e do valor nutritivo de plantas forrageiras.

O seu desenvolvimento virá completar estudos semelhantes iniciados por KOK e seus colaboradores (1, 2 e 3 ) no Departamento da Produção Animal do Estado de São Paulo.

Embora o Instituto Agronômico do Estado, em Campinas, tenha realizado centenas de análises de forragens (4), a escassez de experiências de digestibilidade, em nosso meio, ainda constitui sério obstáculo ao aperfeiçoamento da alimentação animal.

Nossos zootecnistas aplicam coeficientes de digestibilidade, obitidos no estrangeiro, aos princípios nutritivos brutos determinados pela análise química de nossas forragens e assim obtêm os seus teores em princípios nutritivos digestíveis, sôbre os quais calculam as rações. E' este um critério razoável, na falta de melhores elementos, mas está longe de ser acertado. Há, pois, necessidade de um copioso e prolongado trabalho para a obtenção de dados que revelem o real valor nutritivo das forrageiras nativas ou de outras cultivadas em nosso ambiente.

Os autores, no laboratório de bromatologia da 5a. Cadeira, na Escola Superior de Agricultura "Luiz de Queiroz", por meio de análises químicas, determinaram a composição das forragens em estudo; depois, mediante ensaios de digestibilidade com carneiros, estabeleceram os coeficientes de digestibilidade e, com a aplicação dêstes, determinaram os princípios nutritivos digestíveis, através dos quais calcularam finalmente os nutrientes digestíveis totais e a relação nutritiva, segundo MORRISON (5).

Os trabalhos de laboratório foram executados pelo engenheiro-agrônomo Celso Lemaire de Moraes.

O material estudado e os métodos empregados são a seguir descritos. 


\section{MATERIAL E MÉTODOS}

Nesta primeira contribuição, foram estudadas as gramíneas seguintes : Capim jaraguá, Hyparrhenia rufa, (Nees) Stapf.; Capim de Rhodes, Chloris gayana, Kunth.; Milho Santa Rosa, Zea mays, $L$.

As duas primeiras foram experimentadas sob a forma de feno e a última como silagem, o que não impede a aplicação prática dos coeficientes de digestibilidade obtidos às mesmas em estado verde.

O jaraguá, proveniente de terra roxa de baixada, foi cortado antes da floração, com $60 \mathrm{~cm}$. de altura, fenado ao sol e conservado em medas.

O capim de Rhodes, originário de terra roxa de cultura, foi ceifado em plena floração, com $70 \mathrm{~cm}$. de altura, fenado ao sol, mas armazenado em galpão.

O milho foi cultivado em terra roxa adubada com estêrco, sendo plantado em janeiro, em linhas contínuas distanciadas de $55 \mathrm{~cm}$. Foi cortado aos 110 dias de idade, bem espigado, no ponto para ensilagem. Após passar por uma picadeira, foi depositado em um silo cilíndrico subterrâneo revestido de alvenaria e coberto. A silagem foi retirada quatro meses depois, para análise e distribuição aos animais.

A operação de ensilagem e os cuidados posteriores obedeceram à bôa técnica em todos os seus pormenores.

Os ensáios de digestibilidade foram realizados com carneiros, devidamente arreiados e mantidos em baias individuais (Figs. a, b, c, d), conforme os métodos seguidos por MEAD e GUILBERT (6), assim como também por KOK e outros (2).

Os fenos e a silagem foram picados e pesados para as racões diárias, sendo retiradas e dessecadas diàriamente as amostras para análise. Foram feitas quatro análises durante cada ensáio.

As fezes, colhidas também diàriamente, foram sêcas a $100^{\circ} \mathrm{C}$, pesadas e moidas, retirando-se $1 / 10 \mathrm{da}$ quantidade produzida por indivíduo, para análise.

As amostras de alimentos e de fezes foram analisadas, em resumo, segundo os seguintes métodos :

Umidade - Secagem em estufa a $100^{\circ} \mathrm{C}$, até pêso constante;

Cinza - Incineração em mufla a $550^{\circ} \mathrm{C}$, até a obtenção de cinza bem clara;

Matéria graxa - Extração com éter, usando-se extrator de Soxhlet segundo A. O. A. C., pág. 408 (7); 
Proteina - Dosagem do nitrogênio orgânico e amoniacal, segundo Kjeldahl, modificado por Gunning e Arnold (A.O.A. C.), e multiplicado por 6,25 ;

Fibra - Segundo A. O.A.C., pág. 409;

Extrativos não nitrogenados - Determinação por diferença;

Cálcio - Dosagem nas cinzas, segundo A.O.A.C., pág. 119;

Fósforo - Dosagem nas cinzas, segundo A.O.A.C., pág. 22.

As experiências foram feitas com quatro animais simultâneamente, para cada forragem e divididas em dois períodos:

Período preparatório - 9 dias;

Período principal -6 dias.

Resolvemos adotar o período principal de seis dias não só para facilitar o trabalho como também porque os seus resultados são perfeitamente satisfatórios, como se depreende de trabálhos de outros autores ( 8 e 9 ).

Os cálculos dos coeficientes de digestibilidade foram feitos com base nos resultados das análises das forragens e das fezes, na matéria sêca a $100^{\circ} \mathrm{C}$.

\section{RESULTADOS}

1 - Feno de Jaraguá

Quatro carneiros Romney-Marsh.

Ração - 600 gramas por dia e por cabeça.

Período preparatório - 9 dias (17-5-51 a 25-5-51).

Período principal -6 dias (27-5-51 a 1-6-51).

Total de alimentos consumidos e fezes coletadas no período principal (grs.)

\begin{tabular}{l|r|r|r|r}
\hline & \multicolumn{4}{|c}{ Carneiros } \\
\cline { 2 - 5 } & 22 & 282 & 280 & $\mathbf{2 7 9}$ \\
\hline Ração total & & & & \\
Ração total consumida & 2.238 & 2.421 & 2.107 & 2.757 \\
da (sêca a 100 ${ }^{\circ} \mathrm{C}$ ) & 1.932 & 2.019 & 1.819 & 2.380 \\
Fezes coletadas & 1.845 & 2.232 & 2.662 & 2.691 \\
Fezes sêcas a $100^{\circ} \mathrm{C}$ & $\mathbf{9 5 7}$ & 1.048 & $\mathbf{9 4 1}$ & 1.059 \\
\hline
\end{tabular}


Valor nutritivo do feno de jaraguá

\begin{tabular}{l|c|c|c}
\hline & $\begin{array}{c}\text { Nutrientes brutos } \\
\text { (\%) }\end{array}$ & $\begin{array}{l}\text { Coeficientes de di- } \\
\text { gestibilidade (\%) }\end{array}$ & $\begin{array}{c}\text { Nutrientes } \\
\text { digestiveis (\%) }\end{array}$ \\
\hline Umidade & 13,66 & & \\
Matéria sêca & 86,34 & 50,57 & $-43,66$ \\
Proteina & 5,63 & 55,69 & 3,13 \\
Matéria graxa & 2,01 & 51,69 & 1,03 \\
Fibra & 30,21 & 53,46 & 16,15 \\
E. N. Nitroge- & 33,03 & 63,26 & 20,89 \\
nados &
\end{tabular}

Nutrientes digestíveis totais . . . . . . . . . $42,48 \%$

Relação nutritiva . . . . . . . . . . . . . . $1: 12,57$

Relação $\mathrm{CaO}: \mathrm{P}^{2 \mathrm{O} 5} \ldots \ldots \ldots \ldots \ldots \ldots \ldots \ldots \ldots \ldots$. $\ldots \ldots \ldots, 75$

\section{2 - Feno de Rhodes}

Quatro carneiros Romney-Marsh.

Ração - 600 gramas por dia e por cabeça.

Período preparatório - 9 dias (15-6-51 a 23-6-51).

Período principal -6 dias (24-6-51 a 29-6-51).

Total de alimentos consumidos e fezes coletadas no período principal (grs.)

\begin{tabular}{l|r|r|r|r}
\hline & \multicolumn{4}{|c}{ Carn eiros } \\
\cline { 2 - 5 } & 22 & 282 & 280 & 279 \\
\hline Ração total & & & & \\
Ração total consumida & 2.477 & 2.059 & 2.037 & 2.395 \\
da (sêca a 100 $100^{\circ} \mathrm{C}$ ) & 2.202 & 1.767 & 1.749 & 2.057 \\
Fezes coletadas & 1.833 & 2.156 & 2.396 & 2.974 \\
Fezes sêcas a 100 $100^{\circ} \mathrm{C}$ & 941 & 898 & 833 & 951 \\
\hline
\end{tabular}


Valor nutritivo do feno de Rhodes

\begin{tabular}{l|c|c|c}
\hline & $\begin{array}{c}\text { Nutrientes brutos } \\
(\%)\end{array}$ & $\begin{array}{c}\text { Coeficientes de di- } \\
\text { gestibilidade (\%) }\end{array}$ & $\begin{array}{c}\text { Nutrientes } \\
\text { digestiveis (\%) }\end{array}$ \\
\hline Umidade & 14,09 & & \\
Matéria sêca & 85,91 & 53,14 & 45,65 \\
Proteina & 7,19 & 45,56 & 3,27 \\
Matéria graxa & 1,52 & 44,00 & 0,67 \\
Fibra & 21,00 & 56,02 & 11,76 \\
E. N. Nitroge- & 49,22 & 58,20 & 28,64 \\
nados & & 58,20 \\
\hline
\end{tabular}

Nutrientes digestiveis totais . . . . . . . . . 45,18\%

Relação nutritiva . . . . . . . . . . . . . . $1: 12,81$

Relação $\mathrm{CaO}: \mathrm{P}^{2 \mathrm{O}} \ldots \ldots \ldots \ldots \ldots \ldots \ldots \ldots \ldots 1: 0,62$

\section{3 - Silagem de Milho}

Quatro carneiros Romney-Marsh.

Ração - 2.000 gramas por dia e por cabeça.

Período preparatório - 9 dias (5-8-51 a 13-8-51).

Período principal -6 dias (14-8-51 a 19-8-51).

Total de alimentos consumidos e fezes coletadas no período principal. (grs.)

\begin{tabular}{l|r|r|r|r}
\hline & \multicolumn{4}{|c}{ Carneiros } \\
\cline { 2 - 5 } & 22 & 282 & 280 & 279 \\
\hline Ração total & & & & \\
consumida & 7.950 & 10.927 & 8.372 & 10.013 \\
Ração total consumi- & & & & \\
da (sêca a 100 & & \\
Fezes coletadas & 1.594 & 2.326 & 1.782 & 2.131 \\
Fezes sêcas a $100^{\circ} \mathrm{C}$ & 1.336 & 2.849 & 3.094 & 3.192 \\
\hline
\end{tabular}


Valor nutritivo da silagem de milho

\begin{tabular}{l|r|r|r}
\hline & $\begin{array}{r}\text { Nutrientes brutos } \\
(\%)\end{array}$ & $\begin{array}{c}\text { Coeficientes de di- } \\
\text { gestibilidade (\%) }\end{array}$ & $\begin{array}{c}\text { Nutrientes } \\
\text { digestiveis (\%) }\end{array}$ \\
\hline Umidade & 78,71 & & \\
Matéria sêca & 21,29 & 57,50 & 12,24 \\
Proteina & 1,52 & 51,70 & 0,78 \\
Matéria graxa & 0,44 & 68,57 & 0,30 \\
Fibra & 7,05 & 59,88 & 4,22 \\
E. N. Nitroge- & 10,77 & 61,66 & 6,64 \\
nados & & & \\
\hline
\end{tabular}

Nutrientes digestiveis totais . . . . . . . . 12,31\%

Relação nutritiva .. . . . . . . . . . . . . . $1: 14,78$ Relação $\mathrm{CaO}: \mathrm{P} 2 \mathrm{O} 5 \ldots \ldots \ldots \ldots \ldots \ldots$........ 1 : 0,87

\section{RESUMO E CONCLUSÕES}

Os autores apresentam neste trabalho os resultados de ensáios através dos quais estudaram a composição e o valor nutritivo de três gramíneas forrageiras, conforme os quadros I e II.

As experiências de digestibilidade foram feitas com carneiros, segundo a técnica recomendada por MEAD e GUILBERT (6), e as análises realizadas conforme os métodos químicos usualmente empregados, como é esclarecido no texto.

\section{ABSTRACT}

The authors repport in this paper, the results of trials by means of which were determined the composition and nutritive value of three grasses, that are cultivated in Piracicaba, in State of São Paulo, Brazil :

Capim jaragaá, Hyparrhenia rufa, (Nees.) Stapf. (hay); capim de Rhodes, Chloris gayana, Kunth. (hay), and milho Santa Rosa, Zea mays, L. (silage).

The digestion trials were carried out with sheep, following the technique of MEAD and GUILBERT. The chemical analysis of the forages were made by methods usually employed.

The results are in the tables I and II, of this paper. 


\section{BIBLIOGRAFIA}

1. KOK, E. A., ANDRADE, B. M. e MACHADO, L. B. - O Capim de Rhodes - Bol. Ind. Animal. Vol. 5. N. 1-2 : 39-53. São Paulo. 1942.

2. KOK, E. A., MACHADO, L. B. e MEIRELLES, L. V. - Valor nutritivo de plantas forrageiras - Bol. Ind. Animal. Vol. 6. N. 4: 67-83. São Paulo. 1943.

3. KOK, E. A., MACHADO, L. B. e ROCHA, G. L. - Valor nutritivo de plantas forrageiras - Bol. Ind. Animal. Vol. 8. N. 3 : 18-44. São Paulo. 1946.

4. BOI,LIGER, R. - Analyses de Forragens - Publ. do Instituto Agronômico do Estado de São Paulo. Campinas. 1930.

5. MORRISON, F. B. Feeds and Feeding - The Morrison Publishing Company. New York. 1950.

6. MEAD, S. W. e GUILBERT, H. R. - The digestibility of certain fruit by products as determined for ruminants. Bull. 409. University of California. Berkeley. 1926.

7. A.O.A.C. - Official and tentative methods of Analysis of the Association of Official Agricultural Chemists (A.O.A. C.). Sixth editi on. Washington D. C. 1945.

8. L'HARPE, J. DE, PINEYRUA, J. e SUSACQ, J. B. - Investigacion sobre digestibilidad - Anais do II Congresso RioGrandense de Agronomia. 1.o Vol.: 203-216. Rio Grande do Sul. 1940.

9. STAPLES, G. E. e DINUSSON, W. E. - A comparison of relative accuracy between seven-day and ten-day collection periods in digestion trials. Jour. Animal Science. Vol. 10 N. 1 : 244-250. New York. 1951. 
Análises químicas do feno de jaraguá e das fezes. (Médias de todas as análises)

\begin{tabular}{|c|c|c|c|c|c|c|c|c|c|c|c|c|c|c|c|c|}
\hline & \multicolumn{7}{|c|}{$\mathrm{Na}$ matéria sêca a $100^{\circ} \mathrm{C}(\%)$} & \multicolumn{9}{|c|}{ Na matéria úmida $(\%)$} \\
\hline & Prot. & M. G. & Fibra & E. N. N. & Cinza & $\mathrm{CaO}$ & P2O5 & Umid. & M. S. & Prot. & M. G. & Fibra & E. N. N. & Cinza & $\mathrm{CaO}$ & P2O5 \\
\hline $\begin{array}{l}\text { Feno de jaraguá } \\
\text { Fezes do carneiro 22 } \\
\text { Fezes do carneiro 282 } \\
\text { Fezes do carneiro 280 } \\
\text { Fezes do carneiro 279 }\end{array}$ & $\begin{array}{l}6,52 \\
5,85 \\
5,61 \\
5,92 \\
6,01\end{array}$ & $\begin{array}{l}2,32 \\
2,20 \\
2,20 \\
2,31 \\
2,37\end{array}$ & $\begin{array}{l}35,02 \\
32,81 \\
33,90 \\
33,91 \\
30,96 \\
\end{array}$ & $\begin{array}{l}38,24 \\
29,11 \\
27,26 \\
26,79 \\
30,89 \\
\end{array}$ & $\begin{array}{l}17,90 \\
30,03 \\
31,03 \\
31,07 \\
29,77\end{array}$ & $\underline{\underline{E}}$ & $\underline{\underline{Z}}$ & $\begin{array}{l}13,66 \\
48,09 \\
53,04 \\
64,65 \\
60,61 \\
\end{array}$ & $\begin{array}{l}86,34 \\
51,91 \\
46,96 \\
35,35 \\
39,39 \\
\end{array}$ & $\begin{array}{l}5,63 \\
3,03 \\
2,64 \\
2,09 \\
2,36\end{array}$ & $\begin{array}{l}2,01 \\
1,14 \\
1,03 \\
0,81 \\
0,93\end{array}$ & $\begin{array}{l}30,21 \\
16,63 \\
15,91 \\
11,98 \\
12,18 \\
\end{array}$ & $\begin{array}{r}33,03 \\
15,51 \\
12,81 \\
9,49 \\
12,20 \\
\end{array}$ & $\begin{array}{l}15,46 \\
15,58 \\
14,57 \\
10,98 \\
11,72 \\
\end{array}$ & $\underline{\underline{Z}}$ & $\underline{\underline{Z}}$ \\
\hline
\end{tabular}

Coeficientes de digestibilidade do feno de jaraguá

\begin{tabular}{|c|c|c|c|c|c|c|}
\hline & & $\begin{array}{c}\text { Prot. bruta } \\
\% \\
\end{array}$ & $\begin{array}{c}\text { Mat. graxa } \\
\% \\
\end{array}$ & $\begin{array}{c}\text { Fibra } \\
\% \\
\end{array}$ & $\begin{array}{l}\text { E. N. N. } \\
\% \\
\end{array}$ & $\begin{array}{c}\text { Mat. sêca } \\
\% \\
\end{array}$ \\
\hline $\begin{array}{l}\text { Carneiro } \\
\text { Carneiro } \\
\text { Carneiro } \\
\text { Carneiro }\end{array}$ & $\begin{array}{r}22 \\
282 \\
280 \\
279 \\
\end{array}$ & $\begin{array}{r}55,53 \\
55,25 \\
53,03 \\
58,95 \\
\end{array}$ & $\begin{array}{l}53,00 \\
50,78 \\
48,50 \\
54,50 \\
\end{array}$ & $\begin{array}{l}53,57 \\
49,74 \\
49,91 \\
60,63 \\
\end{array}$ & $\begin{array}{l}62,27 \\
62,99 \\
63,76 \\
64,03 \\
\end{array}$ & $\begin{array}{l}50,44 \\
48,08 \\
48,27 \\
55,48 \\
\end{array}$ \\
\hline Média. & & 55,69 & 51,69 & 53,46 & 63,26 & 50,57 \\
\hline
\end{tabular}

Análjses químicas do feno de Rhodes e das fezes. (Médias de todas as análises)

\begin{tabular}{|c|c|c|c|c|c|c|c|c|c|c|c|c|c|c|c|c|}
\hline & \multicolumn{7}{|c|}{ Na matéria sêca a $100^{\circ} \mathrm{C}(\%)$} & \multicolumn{9}{|c|}{ Na matéria úmida (\%) } \\
\hline & Prot. & M. G. & Fibra & E. N. N. & Cinza & $\mathrm{CaO}$ & P2O5 & Umid. & M. $\mathbf{s .}$ & Prot. & M. G. & Fibra & E. N. N. & Cinza & $\mathrm{CaO}$ & $\mathbf{P 2 O 5}$ \\
\hline $\begin{array}{l}\text { Feno de Rhodes } \\
\text { Fezes do carneiro } 22 \\
\text { Fezes do carneiro } 282 \\
\text { Fezes do carneiro } 280 \\
\text { Fezes do carneiro } 279\end{array}$ & $\begin{array}{l}8,37 \\
9,99 \\
9,21 \\
9,90 \\
9,86\end{array}$ & $\begin{array}{l}1,77 \\
2,22 \\
2,01 \\
2,13 \\
2,12 \\
\end{array}$ & $\begin{array}{l}24,56 \\
23,41 \\
22,50 \\
23,11 \\
23,22 \\
\end{array}$ & $\begin{array}{l}57,28 \\
51,24 \\
52,07 \\
50,75 \\
50,19 \\
\end{array}$ & $\begin{array}{r}8,02 \\
13,14 \\
14,21 \\
14,11 \\
14,61 \\
\end{array}$ & $\underline{\underline{Z}}$ & $\underline{\underline{Z}}$ & $\begin{array}{l}14,09 \\
48,65 \\
58,31 \\
65,22 \\
68,01\end{array}$ & $\begin{array}{l}85,91 \\
51,35 \\
41,69 \\
34,78 \\
31,99 \\
\end{array}$ & $\begin{array}{l}7,19 \\
5,12 \\
3,83 \\
3,33 \\
3,15\end{array}$ & $\begin{array}{l}1,52 \\
1,13 \\
0,83 \\
0,74 \\
0,67\end{array}$ & $\begin{array}{r}21,00 \\
12,02 \\
9,38 \\
8,03 \\
7,42 \\
\end{array}$ & $\begin{array}{l}49,22 \\
26,34 \\
21,72 \\
17,78 \\
16,08 \\
\end{array}$ & $\begin{array}{l}6,88 \\
6,74 \\
5,92 \\
4,90 \\
4,67 \\
\end{array}$ & $\underline{0,43}$ & $\underline{\underline{Z}}$ \\
\hline
\end{tabular}

Coeficientes de digestibilidade do feno de Rhodes

\begin{tabular}{|c|c|c|c|c|c|c|}
\hline & $\therefore$ & $\begin{array}{c}\text { Prot. bruta } \\
\% \\
\end{array}$ & $\begin{array}{c}\text { Mat. graxa } \\
\% \\
\end{array}$ & $\begin{array}{c}\text { Fibra } \\
\%\end{array}$ & $\begin{array}{l}\text { E. N. N. } \\
\%\end{array}$ & $\begin{array}{c}\text { Mat. sêca } \\
\%\end{array}$ \\
\hline $\begin{array}{l}\text { Carneiro } \\
\text { Carneiro } \\
\text { Carneiro } \\
\text { Carneiro } \\
\end{array}$ & $\begin{array}{r}22 \\
282 \\
280 \\
279 \\
\end{array}$ & $\begin{array}{l}48,99 \\
44,05 \\
43,68 \\
45,53 \\
\end{array}$ & $\begin{array}{l}46,40 \\
42,28 \\
42,71 \\
44,63 \\
\end{array}$ & $\begin{array}{l}59,27 \\
53,42 \\
55,21 \\
56,21 \\
\end{array}$ & $\begin{array}{l}61,77 \\
53,78 \\
57,80 \\
59,48 \\
\end{array}$ & $\begin{array}{l}57,27 \\
49,16 \\
52,38 \\
53,77 \\
\end{array}$ \\
\hline Média. & .. & 45,56 & 44,00 & 56,02 & 58,20 & 53,14 \\
\hline
\end{tabular}


Análises químicas da silagem de milho e das fezes. (Média de todas as análises)

\begin{tabular}{|c|c|c|c|c|c|c|c|c|c|c|c|c|c|c|c|c|}
\hline & \multicolumn{7}{|c|}{$\mathrm{Na}$ matéria sêca a $100^{\circ} \mathrm{C}(\%)$} & \multicolumn{9}{|c|}{ Na matéria úmida $(\%)$} \\
\hline & Prot. & M. G. & Fibra & E. N. N. & Cinza & $\mathrm{CaO}$ & P2O5 & Umid. & M. S. & Prot. & M. G. & Fibra & E. N. N. & Cinza & $\mathrm{CaO}$ & P2O5 \\
\hline $\begin{array}{l}\text { Silagem de milho } \\
\text { Fezes do carneiro } 22 \\
\text { Fezes do carneiro } 282 \\
\text { Fezes do carneiro 280 } \\
\text { Fezes do carneiro 279 }\end{array}$ & $\begin{array}{r}7,17 \\
.7,91 \\
10,11 \\
6,99 \\
8,18 \\
\end{array}$ & $\begin{array}{l}2,09 \\
1,94 \\
1,51 \\
1,21 \\
1,57\end{array}$ & $\begin{array}{l}33,15 \\
31,15 \\
35,21 \\
28,22 \\
31,91 \\
\end{array}$ & $\begin{array}{l}50,46 \\
45,70 \\
39,75 \\
49,69 \\
45,10 \\
\end{array}$ & $\begin{array}{r}7,13 \\
13,30 \\
13,42 \\
13,89 \\
13,24 \\
\end{array}$ & $\underline{\underline{Z}}$ & $\underline{\square}$ & $\begin{array}{l}78,71 \\
48,80 \\
72,19 \\
71,21 \\
71,24 \\
\end{array}$ & $\begin{array}{l}21,29 \\
51,20 \\
27,81 \\
28,79 \\
28,76 \\
\end{array}$ & $\begin{array}{l}1,52 \\
4,04 \\
2,81 \\
2,01 \\
2,35 \\
\end{array}$ & $\begin{array}{l}0,44 \\
0,99 \\
0,41 \\
0,34 \\
0,45 \\
\end{array}$ & $\begin{array}{r}7,05 \\
15,94 \\
9,79 \\
8,12 \\
9,17 \\
\end{array}$ & $\begin{array}{l}10,77 \\
23,43 \\
11,07 \\
14.33 \\
12,96 \\
\end{array}$ & $\begin{array}{l}1,51 \\
6,80 \\
3,73 \\
3,99 \\
3,83 \\
\end{array}$ & $\underline{E}$ & $\underline{\square}$ \\
\hline
\end{tabular}

Coeficientes de digestibilidade da silagem de milho

\begin{tabular}{|c|c|c|c|c|c|c|}
\hline & & $\begin{array}{c}\text { Prot. bruta } \\
\%\end{array}$ & $\begin{array}{c}\text { Mat. graxa } \\
\% \\
\end{array}$ & $\begin{array}{c}\text { Fibra } \\
\% \\
\end{array}$ & \begin{tabular}{|c|c|} 
E. N. N. \\
$\%$
\end{tabular} & $\begin{array}{c}\text { Mat. sêce } \\
\%\end{array}$ \\
\hline $\begin{array}{l}\text { Carneiro } \\
\text { Carneiro } \\
\text { Carneiro } \\
\text { Carneiro } \\
\end{array}$ & $\begin{array}{r}22 \\
289 \\
230 \\
279 \\
\end{array}$ & $\begin{array}{l}52,67 \\
51,98 \\
51,28 \\
50,87 \\
\end{array}$ & $\begin{array}{l}60,17 \\
75,40 \\
71,09 \\
67,65 \\
\end{array}$ & $\begin{array}{l}59,68 \\
63,83 \\
57,46 \\
58,55 \\
\end{array}$ & $\begin{array}{l}61,14 \\
73,17 \\
50,82 \\
61,51 \\
\end{array}$ & $\begin{array}{l}57,10 \\
65,94 \\
50,02 \\
56,94 \\
\end{array}$ \\
\hline Média. & $\ldots$ & 51,70 & 68,57 & 59,88 & 61,66 & 57,50 \\
\hline
\end{tabular}


QUADRO I - Composição química das forrageiras

\begin{tabular}{|c|c|c|c|c|c|c|c|c|c|c|c|c|}
\hline \multirow{2}{*}{ Nome vulgar } & \multirow{2}{*}{ Nome científico } & \multirow{2}{*}{$\begin{array}{l}\text { Estágio de desenvolvi- } \\
\text { mento }\end{array}$} & \multirow{2}{*}{ Forma } & \multicolumn{9}{|c|}{ Composição química Nutrientes brutos \%) } \\
\hline & & & & Umid. & M. S. & Prot. & M. G. & Fibra & E. N. N. & Cinza & $\mathrm{CaO}$ & P2O5 \\
\hline Capim jaraguá & $\begin{array}{c}\text { Hyparrhenia rufa } \\
\text { (Ness) Stapf. }\end{array}$ & Antes da floração & Feno & 13,66 & 86,34 & 5,63 & 2,01 & 30,21 & 33,03 & 15,46 & 0,53 & 0,40 \\
\hline Capim de Rhodes & $\begin{array}{c}\text { Chloris gayana } \\
\text { (Kunth) }\end{array}$ & Plena floração & Feno & 14,09 & 85,91 & 7,19 & 1,52 & 21,00 & 49,22 & 6,88 & 0,43 & 0,27 \\
\hline Milho Sta. Rosa & Zea mays $\mathrm{L}$. & $\begin{array}{c}\text { Inicio de maturação } \\
\text { dos grãos }\end{array}$ & Silagem & 78,71 & 21,29 & 1,52 & 0.44 & 7,05 & 10,77 & 1,51 & 0,08 & 0,07 \\
\hline
\end{tabular}

QUAADRO II - Digestibilidade e valor nutritivo das forrageiras

\begin{tabular}{|c|c|c|c|c|c|c|c|}
\hline \multirow[b]{2}{*}{ Nutrientes } & \multicolumn{3}{|c|}{ Feno de jaraguá } & \multicolumn{2}{|c|}{ Feno de Rhodes } & \multicolumn{2}{|c|}{ Silagem de milho } \\
\hline & Coef. de & $\begin{array}{l}\text { digestibilidade } \\
(\%)\end{array}$ & $\begin{array}{c}\text { Nutrientes digestiveis } \\
(\%)\end{array}$ & $\mid$\begin{tabular}{c|} 
Coef. de digestibilidade \\
$(\%)$
\end{tabular} & \begin{tabular}{|c|} 
Nutrientes digestiveis \\
$(\%)$
\end{tabular} & $\begin{array}{c}\text { Coef. de digestibilidade } \\
(\%)\end{array}$ & $\begin{array}{c}\text { Nutrientes digestiveis } \\
(\%)\end{array}$ \\
\hline $\begin{array}{l}\text { Matéria sêca } \\
\text { Proteina } \\
\text { Matéria graxa } \\
\text { Fibra } \\
\text { E. N. Nitrogenados }\end{array}$ & & $\begin{array}{l}\mathbf{5 0 , 5 7} \\
\mathbf{5 5 , 6 9} \\
\mathbf{5 1 , 6 0} \\
\mathbf{5 3 , 4 6} \\
\mathbf{6 3 , 2 6} \\
\end{array}$ & $\begin{array}{r}43,66 \\
3,13 \\
1,03 \\
16,15 \\
20,89 \\
\end{array}$ & $\begin{array}{l}53,14 \\
45,56 \\
44,00 \\
56,02 \\
58,20 \\
\end{array}$ & $\begin{array}{r}45,65 \\
3,27 \\
0,67 \\
11,76 \\
28,64 \\
\end{array}$ & $\begin{array}{l}57,50 \\
51,70 \\
68,57 \\
59,88 \\
61,66\end{array}$ & $\begin{array}{r}12,24 \\
0,78 \\
0,30 \\
4,22 \\
6,64\end{array}$ \\
\hline \multicolumn{3}{|c|}{$\begin{array}{l}\text { Nutrientes digestiveis totais } \\
\text { Relação nutritiva } \\
\text { Relação } \mathrm{CaO}: \mathrm{P2O}\end{array}$} & \begin{tabular}{|c|}
$42,48 \%$ \\
$1: 12,57$ \\
$1: 0,75$
\end{tabular} & \multicolumn{2}{|l|}{$\begin{array}{c}45,18 \% \\
1: 12,81 \\
1: 0,62 \\
\end{array}$} & \multicolumn{2}{|l|}{$\begin{array}{r}12,31 \% \\
1: 14,78 \\
1: 0,87 \\
\end{array}$} \\
\hline
\end{tabular}




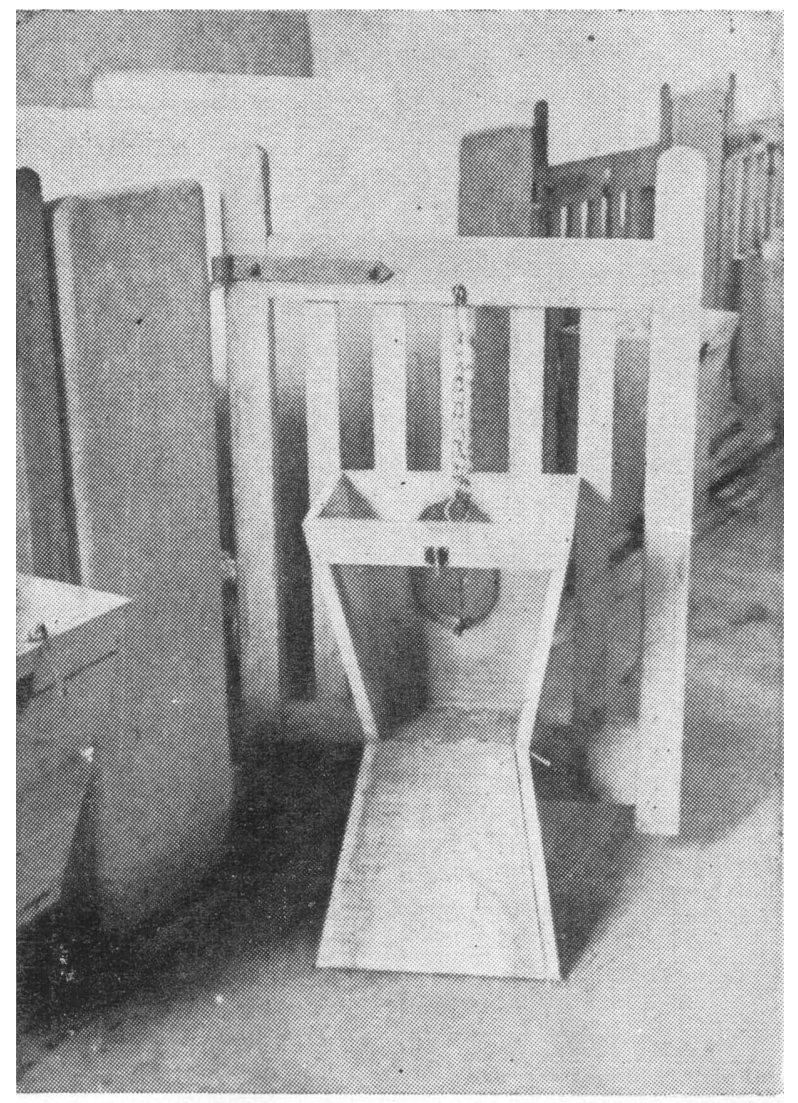

Figura a 


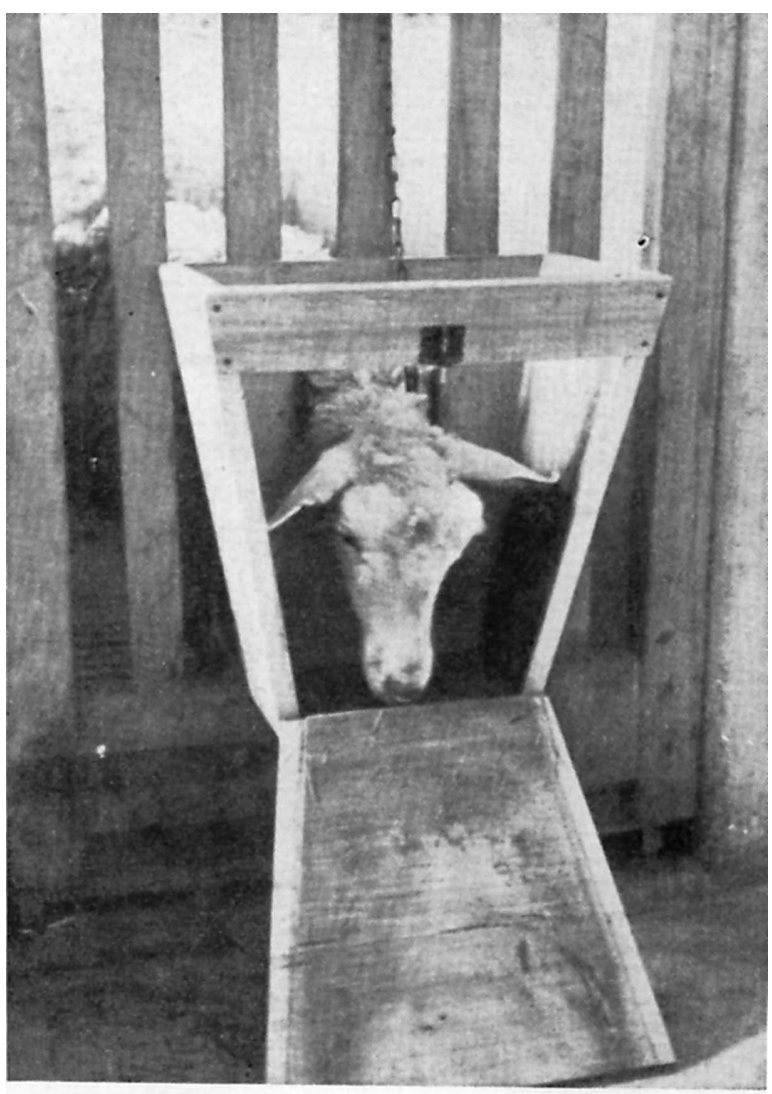

Figura b 


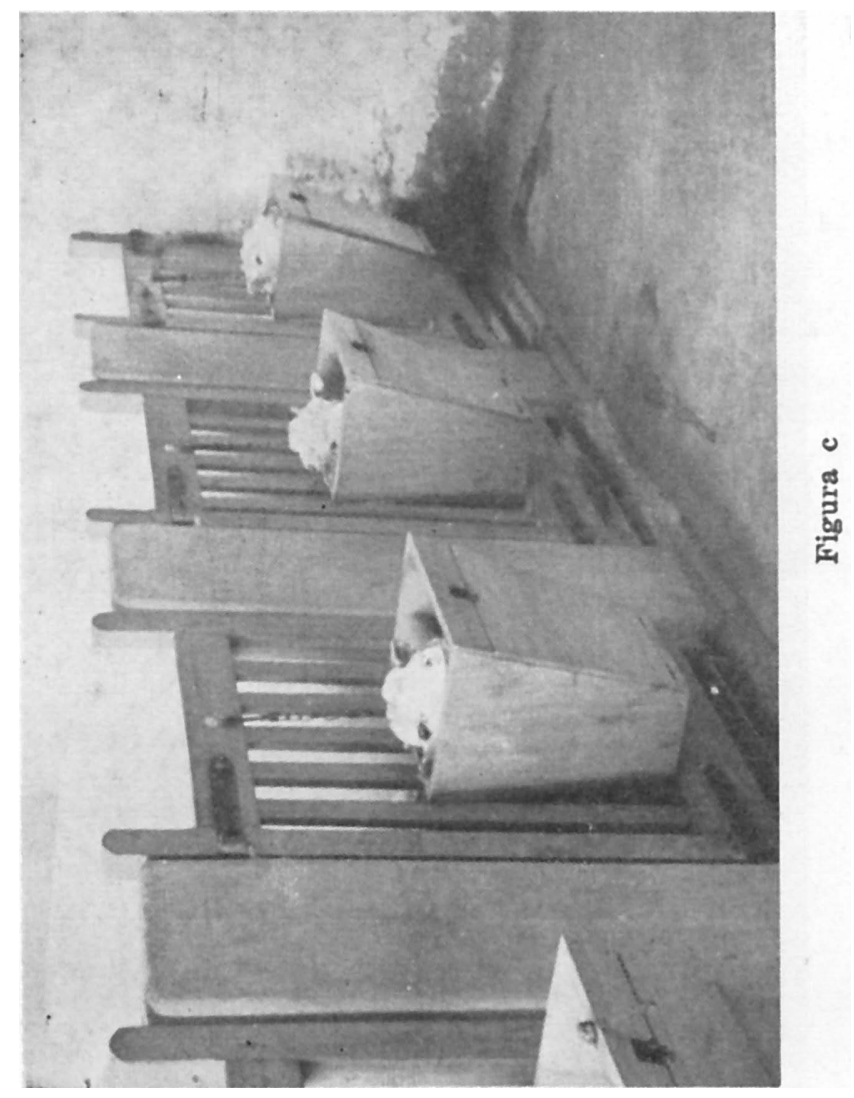




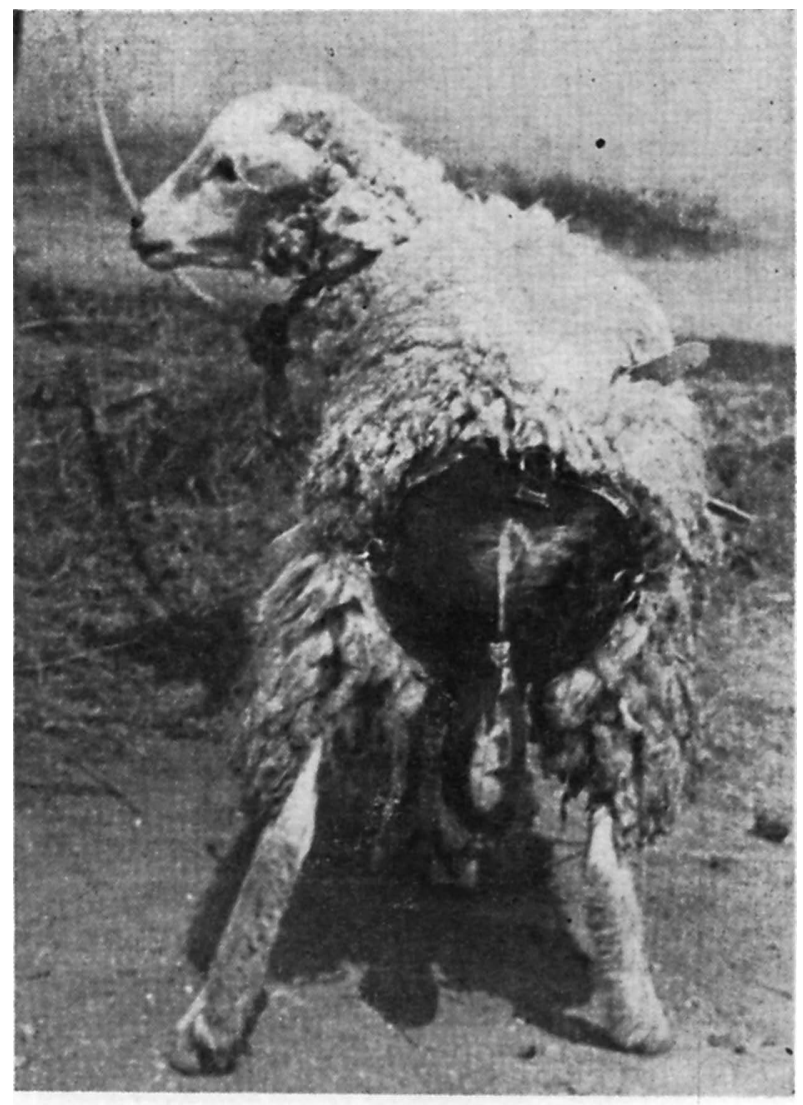

Figura d 